Pontifícia Universidade C Católica

Gláucia Luciana Drumond Bispo

\title{
Movimento, Relação e Geração: Uma Análise das Potências de Eros No "Banquete" de Platão
}

MONOGRAFIA

DEPARTAMENTO DE FILOSOFIA PROGRAMA DE PÓS-GRADUAÇÃO

RIO DE JANEIRO

DEZEMBRO DE 2017 


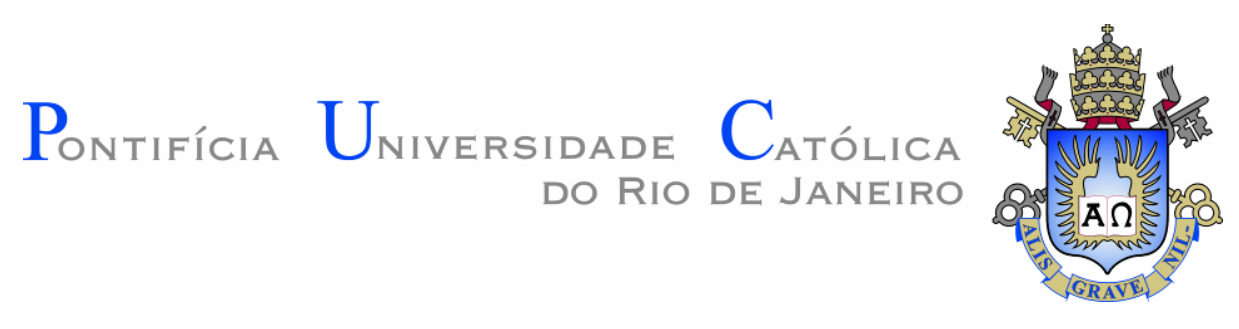

DEPARTAMENTO DE FILOSOFIA

Especialização em Filosofia Antiga

Movimento, Relação e Geração:

Uma Análise Das Potências de Eros No "Banquete" De Platão

Gláucia Luciana Drumond Bispo

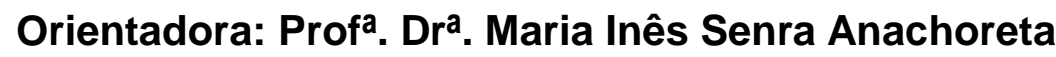




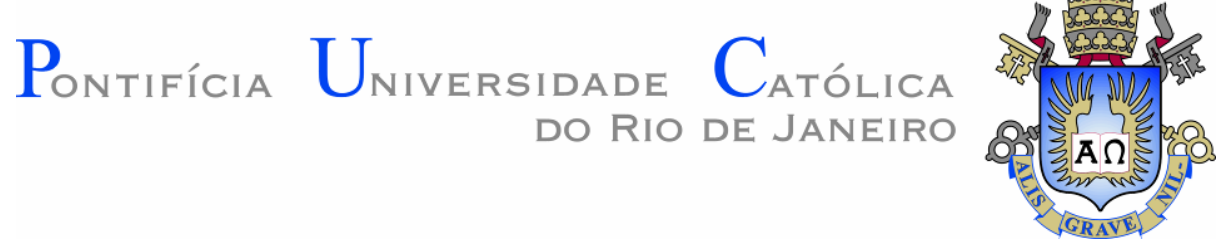

\section{Gláucia Luciana Drumond Bispo}

Movimento, Relação e Geração:

Uma Análise das Potências de Eros no "Banquete" de Platão

Monografia de Especialização

Monografia apresentada à Pontifícia Universidade Católica do Rio de Janeiro, como requisito parcial para a obtenção do título de Especialista em Filosofia Antiga.

Orientadora: Prof ${ }^{a}$. Drª . Maria Inês Senra Anachoreta 


\title{
Gláucia Luciana Drumond Bispo
}

\begin{abstract}
Movimento, Relação e Geração: Uma Análise das Potências de Eros no "Banquete" de Platão

Monografia apresentada à Pontifícia Universidade Católica do Rio de Janeiro, como requisito parcial para a obtenção do título de Especialista em Filosofia Antiga.
\end{abstract}

Orientadora: Prof ${ }^{a}$. Dra ${ }^{\text {. }}$. Maria Inês Senra Anachoreta

Profa. Dra. Maria Inês Senra Anachoreta Orientadora Departamento de Filosofia UERJ/PUC-RIO

Profo. Dr. Marcus Reis Pinheiro Parecerista Departamento de Filosofia UFF/PUC-RIO

Profo. Dr. Remo Mannarino Filho Departamento de Filosofia PUC-RIO

Profa. Irley Fernandes Franco Coordenadora do Curso de Especialização em Filosofia Antiga - PUC-RIO 
Dedico esta monografia ao meu pai e à minha mãe, os melhores e os maiores guias eróticos da minha vida: mais do que oferecer o que foi possível prover, me ensinaram a buscar... sempre. 


\section{AGRADECIMENTOS}

A todos aqueles que contribuíram para a minha formação pessoal, acadêmica e profissional: à minha mãe, Antônia Drummond, pela valorização e incentivo aos estudos desde pequena; ao meu pai, José Antônio Bispo, pelas conversas filosóficas, que na época eu não era capaz de compreender; à minha tia Vera Lúcia, por ter sido um dos melhores seres humanos com o qual pude conviver.

Agradeço, especialmente, ao meu eterno professor Carlos Diógenes Tourinho (UFF), que me inseriu, oficialmente, no mundo filosófico. Nas suas aulas sobre Parmênides percebi que os questionamentos que eu fazia a respeito da vida, do mundo, quando criança, não eram triviais.

À minha para sempre professora e orientadora, Maria Inês Senra Anachoreta, pela sua atenção, paciência, lealdade, respeito e dedicação no processo de construção desta monografia. Pelas conversas infindáveis sobre Eros e sua relação com a vida, que foram únicas para o meu crescimento pessoal, acadêmico e profissional. E ainda, pelo incentivo aos estudos posteriores ao curso de especialização. Desejo um mundo de professoras de Filosofia como você!

Agradeço ao meu querido Abbé Tossa, pelo objeto de estudo deste trabalho. A relação que vivemos foi a experiência necessária à minha investigação sobre o Amor na Filosofia.

À minha brilhante e musa da memória Aline Bezerra de Menezes, pelo apoio e acompanhamento inicial desta pesquisa. Pela severidade sincera e necessária nas incontáveis versões dessa investigação. Pessoa fundamental para o meu amadurecimento intelectual e pessoal. Foi, é e será sempre uma grande honra compartilhar momentos grandiosos com esta figura ímpar que és tu.

Ao meu amigo Zal Bueno, pela escuta e incentivo ao estudo do idioma Grego. Tenho profunda admiração pela sua pessoa. Foi um presente ter lhe conhecido.

Aos meus colegas do grupo de pesquisa de Filosofia Antiga da UERJ, pela escuta e pelas sugestões apresentadas referentes a este trabalho. $O$ estudo coletivo de textos e obras platônicas foi crucial para a produção desta pesquisa. Sem o diálogo, sem as diversas apresentações realizadas no grupo e as demais experiências que a permanência no mesmo me proporcionou não teria sido possível chegar até aqui. Muitíssimo obrigada!

Aos meus colegas da turma de Grego (CLAC - UFRJ), Pablo Marques, João Marcos e Frederico Augusto, nosso rapsodo preferido, por me escutarem falar de Eros durante os intervalos e por promoverem momentos divertidos em torno do que eu expunha. Tenham certeza de que tornaram o processo doloroso da escrita mais leve. Vocês são especiais!

Ao Gabriel Heil, o monitor da turma de Grego, pela paciência e atenção especial dedicada ao ensino do difićlimo idioma Grego; pela valorização e respeito às minhas perguntas sobre termos gregos específicos. Suas respostas e dicas colaboraram para a compreensão de questões referentes ao presente trabalho. Agradeço, imensamente, pela sugestão de livros de literatura grega e outras que ajudaram a ampliar a minha visão de mundo. Agradeço por ter me ensinado o alfabeto grego e 
o maldito particípio. Aprendi muito com você, apesar do seu jeito "pamonha" de ser!

À minha inteligentíssima amiga (amiga mesmo) e irmã Gracyelle Costa, que é uma figura extremamente importante na minha vida. Agradeço pela sua escuta, pelo seu apoio e pelos momentos de catarse que somente você sabe promover para nós. Sei que sempre posso contar com você!

À Tainá Julio, por ser uma diva inspiradora para a minha vida pessoal e profissional. É uma honra compartilhar esta vitória com você.

À Vanessa Castro, pelas caronas e escuta em torno do parto que é o fazer monográfico.

Ao povo da Acqua Esporte Academia. Este lugar foi de extrema importância para extravazar todas as minhas angústias e frustrações ao longo do processo de escrita desta monografia. Agradeço, especialmente, aos professores André Luiz e Luiz Galvão pelos gritos de incentivo e às parceiras de treino, Silvania Santos, Ana Paula Santana, Milena Santana e Verônica Moraes por serem musas inspiradoras.

À Caroline de Almeida, por não me deixar esmorecer nos treinos; pela escuta das minhas angústias "monografescas" e, principalmente, por me suportar nos dias difíceis.

À minha turma querida (1.103/1.203) de alfabetização a qual tive a oportunidade de acompanhar desde o ano passado até aqui. Sou eternamente grata por vocês fazerem de mim uma bela professora (amante) e que eu possa continuar fazendo de tudo para o crescimento pessoal e intelectual de vocês. Não tenho dúvidas de que o Eros filosófico foi vivenciado com esta turma, tornando indispensáveis os dizeres de Rubem Alves, em uma Carta a um Amigo: "Não havíamos marcado hora, não havíamos marcado lugar. E, na infinita possibilidade de lugares, na infinita possibilidade de tempos, nossos tempos e nossos lugares coincidiram. E, deu-se o encontro". Foi uma honra imensa ter vivenciado cada minuto deste encontro com essas crianças.

Às minhas colegas de turma do curso de Especialização em Filosofia Antiga, Cláudia Guimarães, Ângela Fleurry, Débora Prestes, Natália Pinheiro, Pauliane Oliveira e ao meu amigo Michael Holanda, por compartilharem alegrias e desesperos existenciais; pelas conversas no metrô da superfície, pelas idas ao Teatro. Muito obrigada pelo apoio e philia de vocês.

À Secretaria do Curso de Especialização em Filosofia Antiga, pelos esclarecimentos prestados no processo de finalização deste trabalho.

Enfim, agradeço muitíssimo a todos os meus professores e professoras que contribuíram para a minha permanência no campo da Filosofia e a todos os meus parceiros de luta, que não foram citados aqui, pelos momentos de escuta e compartilhamento das alegrias e das tristezas acadêmicas e não-acadêmicas. 


\section{RESUMO}

Esta monografia tem como objetivo explorar as potências de Eros - movimento, relação e geração -, identificadas no estudo do “discurso" de Sócrates n'O Banquete, de Platão. Visa, ainda, relacionar tais potências à fórmula " $1+1=3$ ", apresentada por Jean-Pierre Vernant em um dos seus artigos sobre Eros. Com isso, buscamos, em primeiro lugar, demonstrar como cada uma das parcelas da fórmula supracitada se vincula às potências eróticas mencionadas n'O Banquete. Em seguida, analisamos cada potência, individualmente, ratificando e justificando a posição que cada uma delas ocupa na fórmula de Vernant. Verificamos, em nossa pesquisa, que o impulso pela busca do objeto desejado (movimento), as uniões entre os diversos seres existentes (relações) e a produção (geração) oriunda da busca e das relações sinalizadas estão vinculadas à ação de Eros, uma força intrínseca (mediadora/intermediária) que provoca a relação de seres distintos para gerar novas unidades. Eros, desta forma, revelou-se para nós como um acúmulo de potências expresso em " $1+1=3$ ", que traduzido em palavras apresenta-se como "movimento+relação=geração".

Palavras-chave:

Eros. Movimento. Relação. Geração. 


\begin{abstract}
This monograph aims to explore the powers of Eros - movement, relation and generation - identified in Plato's study of Socrates' "discourse" in Banquet. It is also intended to relate these powers to the formula " $1+1=3$ ", presented by JeanPierre Vernant in one of his articles on Eros. With this, we seek, firstly, to demonstrate how each of the portions of the aforementioned formula is linked to the erotic powers mentioned in the Banquet. Then we analyze each power, individually, ratifying and justifying the position each of them occupies in Vernant's formula. In our research, we verified that the impulse to search for the desired object (movement), the unions between the various existing beings (relations) and the production (generation) originated from the search and the signalized relations are linked to the action of Eros, a force intrinsic (mediator / intermediary) that provokes the relation of distinct beings to generate new units. Eros, in this way, has proved to us as an accumulation of powers expressed in "1+ $1=3 "$, which translates into words presented as "movement + relation = generation".
\end{abstract}

Key words:

Eros. Movement. Relationship. Generation. 


\section{EPÍGRAFE}

Tolos são aqueles que, seduzidos pela multiplicidade, se entregam vorazmente a ela. Eles acabam tendo uma terrível indigestão... Sábios são aqueles que da multiplicidade, escolhem o essencial.

Rubem Alves (1933-2014) 


\section{SUMÁRIO}

\section{INTRODUÇÃO, p. 10}

\section{Eros: Potência de Movimento, p. 18}

1.1. Eros originário e gerado pelo movimento, p. 20

1.1.1. Pênia: a busca [impulsionada] pela necessidade - movimento sem fim específico, p. 22

1.1.2. Expediente: a abundância de recursos - a sonolência e o repouso, p. 23

1.1.3. Eros: a síntese da falta e do recurso - o movimento direcionado, p. 24

\section{Eros: Potência de Relação, p. 29}

2.1. Diálogo: 0 acesso à verdade sobre Eros, p. 31

2.1.1. O diálogo entre Sócrates e Agatão (199c-201c), p. 34

2.1.1.1. A transição entre as falas de Agatão e Sócrates, p. 35

2.1.1.2. Diotima e o mito do nascimento de Eros, p.39

\section{Eros: Potência de Geração, p. 41}

3.1. Da Geração: Os Mistérios do Amor, p. 42

3.1.1. Dos Mistérios Menores, p. 43

3.1.2. Dos Mistérios Maiores, p. 46

Considerações Finais, p. 63

Referência Bibliográfica, p. 70 
